\title{
A Multisite Study Demonstrates Positive Impacts to Systems Thinking Using a Table-top Simulation Experience
}

Jill S. Sanko, PhD, MS, APRN, CHSE-A, FSSH; Karina Gattamorta, PhD, EdS; Judith Young, DNP, RN, CNE; Carol F. Durham, EdD, RN, ANEF, FAAN, FSSH; Gwen Sherwood, PhD, RN, FAAN, ANEF; and Mary Dolansky, PhD, RN, FAAN

\begin{abstract}
(150)
Background

Despite merits of systems thinking identified in the literature, systems thinking, the ability to recognize, understand, and synthesize interactions and interdependencies in a set of components designed for a purpose is not yet consistently integrated into healthcare programs.
\end{abstract}

Purpose

This study examined the impacts of a table-top simulation designed to teach systems thinking on systems thinking scores in a variety of pre and post-licensure healthcare students.

\section{Methods}

A multi-site study was conducted across five academic institutions targeting both graduate and pre-licensure students enrolled in nursing, medicine, physical therapy, public health, psychology, and pharmacology programs.

Results

Statistically significant impacts on systems thinking were found overall as well as in most of the groups studied.

This is the author's manuscript of the article published in final edited form as:

Sanko, J. S., Gattamorta, K., Young, J., Durham, C. F., Sherwood, G., \& Dolansky, M. (2021). A Multisite Study Demonstrates Positive Impacts to Systems Thinking Using a Table-top Simulation Experience. Nurse Educator, 46(1), 29-33. https://doi.org/10.1097/NNE.0000000000000817 


\section{Conclusions}

The use of the table-top simulation Friday Night at the ER was found to improve systems thinking across a wide variety of health-related majors including nursing, medicine, public health, physical therapy, and psychology.

\section{Key words}

Systems thinking, Simulation, Healthcare, Education

\section{Background}

Systems thinking is defined "as a process applied to individuals, teams, and organizations to impact cause and effect where solutions to complex problems are accomplished through collaborative effort according to personal ability with respect to improving components and the greater whole" (Stalter,et al., 2017,pg 323). Cited as key in improving both the safety of systems (Stalter, et al, 2017) and systems as a whole (Swanson, et al., 2012), systems thinking is the ability to recognize, understand, and synthesize interactions and interdependencies in a set of components designed for a purpose (Waldman \& Schargel, 2006).

Successful navigation and in turn, successful healthcare outcomes depend on the development of the skills of relationship building, negotiating, and communicating within and across systems. Lucien Leape (2009), a pioneer of the healthcare safety movement stressed the importance of systems thinking; "systems cannot be improved if there is not an understanding of them". Systems thinking is widely included in training and educational curricula of disciplines outside healthcare that are equally complex, but have better safety outcomes (Swanson, et al., 2015). With some sources estimating over 400 thousand deaths occur each year as a result of preventable healthcare errors (Mckary \& Daniels, 2017), a vast majority of which are tied to 
systems failures (Vincent \& Amalberti, 2016), the exclusion of systems thinking in healthcare curricula for professionals and students appears irresponsible. Despite the clear merits of systems thinking identified in the literature, systems thinking is not yet consistently integrated into healthcare programs (Dolansky \& Moore, 2013; Plack, Goldman, Scott, et al, 2018). Even with salient reasons and decade old recommendations to focus on systems-level education, there remains no mandate to teach systems thinking as a required topic in healthcare education (Frenk et al. 2010).

Evidence supports simulation as an effective technique to teach topics where skills and knowledge meet application of learned concepts. Friday Night at the $\mathrm{ER}^{\circledR}$ (FNER) is a table-top team-learning simulation experience designed to teach the core concepts of systems thinking (innovation, collaboration, and using data in decision making) (Gardner, 2019). FNER is a commercially available experiential learning simulation designed to teach systems thinking using a simulated hospital environment that simulates 24 hours in the context of hospital patient flow and staffing to allow learners to elevate their thinking from the perspective of an individual minded thinker to that of a systems level thinker. The simulation activity further enables learners to uncover implicit biases that may present barriers in changing mental models that may make one beholden to a "because we have always done it that way mentality" rather than one willing to innovate and collaborate with others. FNER has been on the market for over 20 years and has been widely used in a multitude of healthcare and non-healthcare organizations to teach systems thinking. Despite its moniker, FNER does not require players to have any healthcare knowledge to learn from it, therefore it can be used to teach learners at any stage of their education.

A few studies have explored learner impacts of FNER in nursing education (ThortonBacon, Trent, \& McCoy, 2018; Young, 2018), however gaps remain with regard to broader 
usages and subsequent learner outcomes. This study sought to expand what is known exploring the effect of FNER on systems thinking across a variety of healthcare students and academic programs employing FNER in their curricula. Research questions included: 1 . What is the overall impact of participating in Friday Night at the ER on Systems Thinking measured by the Systems Thinking Scale? 2. Are there differences in the impacts of participating in Friday Night at the ER on Systems Thinking moderated by gender, degree sought, length of BSN degree, or discipline studied?

\section{Methods}

A multi-site study was conducted across five academic institutions (Table 1) targeting both graduate and pre-licensure students enrolled in nursing, medicine, physical therapy, public health, psychology, and pharmacology programs.

\section{Sample and Setting}

A convenience sample was recruited from programs who had implemented FNER and expressed interest in participating in learning more about the outcomes of participation. Leaders at each site (co-authors of this paper) explained the study and participants could opt out if they did not want their data included.

\section{Instrument}

The Systems Thinking Scale (STS) was used to measure the impact of participation in FNER on systems thinking (Moore \& Dolansky, 2010). The Systems Thinking Scale is a tool designed to measure the construct of systems thinking. Moore and Dolansky (2010) completed initial testing of the STS to establish preliminary psychometric data for the STS. Following the first round of analysis, changes to the tool were made guided by initial psychometric test results. 
A subsequent analysis was completed. Results of the second analysis demonstrated good discriminate validity, low concurrent-criterion-related validity using a comparison of the Quality Improvement Knowledge Application Tool with the STS. Good reliability was found with a Chronbach's of $\alpha=0.82$. The STS is completed using a 5-point Likert scale $(0=$ Never to $4=$ Most of the time). Item scores are summed to provide a total STS score, with a possible range from 0-80 (20 items) and higher scores indicating better systems thinking. Psychometric analysis was completed prior to hypothesis testing.

\section{Data Collection}

Data were collected across all participating sites and then merged into a single data base for analysis. The STS was administered prior to and following participation in a FNER session, allowing for the analysis of the impact of time. Each institution had trained FNER facilitators conducting the FNER sessions.

\section{Human Subjects Review}

Each participating institution obtained institutional review board approval to administer the STS to learners participating in FNER sessions at their institutions. The IRB at each institution independently reviewed the proposal and deemed the project exempt as an educational quality improvement study.

\section{Results}

Psychometric analysis of the STS 
Scale analysis was used to examine the psychometric properties of the single factor tool. Good reliability, $\alpha=.994$ ) and good internal consistency, with all item-total correlations $>.410$ were found.

Data analysis

Each institution submitted their data yielding a total of 395 paired samples available for analysis (Table 2). STS total scores were calculated by summing the scores from the items included in the STS measure; these scores were then used to compare outcomes. Paired t-tests and Analysis of Variance (ANOVA) were used to analyze the data.

To answer research question one: What is the overall impact on participating in Friday Night at the ER on Systems Thinking as measured by the Systems Thinking Scale? a paired t-test analysis was employed. Findings from this analysis demonstrated a significant time effect, $t$ $(420)=-5.64, p<.001$, pre -FNER STS score $M=58.02, S D=9.79$ and post-FNER STS score $M$ $=60.03, S D$ 10.32) with a modest effect size was, $d=.20$.

To answer research question two: Are there differences in the impacts of participating in Friday Night at the ER on Systems Thinking moderated by gender, degree sought, length of BSN degree, or discipline studied? mixed ANOVAs examining the effect of time (pre to post changes) and between subjects variables including gender, degree sought (graduate versus undergraduate nursing, length of nursing program (traditional [T-BSN], accelerated [AO-BSN], RN-BSN), and discipline studied was used.

Between subjects analyses demonstrated insignificant interaction (moderating) effects for all comparisons (Table 3). Participation in FNER improves systems thinking regardless of discipline studied $\left[F(1,389)=10.82, p<.001, \mathrm{y}^{2}=.027\right]$, gender of the individual, $[F(1,397)=$ 
$\left.17.15, p<.001, \mathrm{y}^{2}=0.041\right]$, or type nursing degree, $\left[F(1,263)=9.29, p=.003, \mathrm{y}^{2}=.034\right]$.

Participation in FNER did not significantly impact systems thinking when examining interactions based on level of degree (undergraduate vs graduate), $p=.557$. For analyses completed exploring the moderating impacts of length of BSN program, significant differences were found, between the AO-BSN and T-BSN programs. AO-BSN students had significantly different means AO-BSN, $M=59.91$, T-BSN, $M=56.63,95 \%$ CI [ $1.095-5.454], p=.003$. Although a statistically significant time effect was not found, an improvement in systems thinking was for both groups, AO-BSN; pre-mean $=59.36$, post-mean $=60.45, p=.347$, T-BSN; pre-mean $=55.78$, post-mean $=57.48, p=.168$.

\section{Discussion}

Given the ease of implementing the Friday Night in the ER Simulation in a variety of healthcare curricula and its demonstrated impacts in improving key knowledge for systems thinking in healthcare professions' learners it is recommended that professional schools consider integrating FNER simulation into curricula for the purposes of improving systems thinking Findings demonstrated effectiveness in improvements in systems thinking as measured by the STS regardless of the discipline in which the area of study participants were completing, which gender they were, or which nursing degree pursued (BSN, RN-BSN, MSN). Differences noted between the traditional BSN and AO-BSN students may be related to age, life experience, and knowledge. AO-BSN students all had attained prior college degrees, whereas T-BSN students were more likely to be seeking their first college degree. Even with this finding, participation still had positive impacts in improving systems thinking for these groups.

The broad impacts demonstrated in this study support the notion that similar effectiveness on systems thinking could be found if healthcare professionals were to participate in a FNER 
simulation experience. Important in examining the use of FNER in a clinical context could be impacts to important healthcare outcomes such as mitigation of errors through better communication, collaboration and coordination of care. Further study in an actual healthcare setting would be needed to better understand how using FNER in a clinical context might impact systems thinking and ultimately patient safety.

\section{Limitations}

This study had several limitations including examining the impacts of a single activity at a single point in time to improve systems thinking rather than longitudinally. Little data is available to compare results of this study with other approaches to improve systems thinking. The study did not include a longitudinal view to examine term long term impacts to systems thinking or the need for spaced reinforcement of concepts to assist in retention of the improvement in systems thinking. Finally, because the impacts of FNER on systems thinking was undertaken solely in a student population it is possible that the findings are not generalizable to all post-licensure professionals, however given the inclusion of RN-BSN students and the noted impacts in this population, there is some confidence that generalizability is feasible.

Strengths of the study include the broad context of which the application of FNER was studied, the use of trained facilitators, and the use of an established tool to measure the outcome of interest. Including various disciplines across five institutions offered a broader application than a single location.

\section{Conclusion}

The use of Friday Night at the ER to improve systems thinking was found across a wide variety of health-related majors including nursing, medicine, public health, physical therapy, and 
psychology (pharmacy students participated in FNER sessions, but no paired data was available for analysis). The demonstration of the effectiveness of participating in FNER simulations across a variety of healthcare students assists in demonstrating its broad applicability to effect change in systems thinking. The similarity of outcomes found regardless of discipline studied demonstrates potential wide-ranging uses for FNER irrespective of the healthcare discipline. Further, the findings suggest a potential benefit of participation in FNER for healthcare professionals themselves. Inclusion of post-licensed students (RN-BSN) who were already working in their field also begins to demonstrate the potential impacts on systems thinking in working healthcare professionals. Given that only licensed nurses fell into this category, further study in professionals outside of nursing is necessary.

Overall, the study provided evidence that a commercially available, relatively inexpensive table-top simulation can make improvements in a key factor in improving healthcare through systems thinking. Certainly, such knowledge and skill in emerging healthcare providers as they begin their careers can help shift the healthcare culture to pay more attention to the importance of systems interactions between collaboration, innovation and data, which can impact patient and healthcare outcomes. It will be up to educators to explore ways to include such activities and determine the optimal placement in programming for maximal effectiveness. 


\section{References}

Dolansky MA, Moore SM. Quality and safety education for nurses (QSEN): The key is systems thinking. Online Journal of Issues in Nursing. 2013;18(3): doi: 10.3912/OJIN.Vol18No03Man01.

Frenk J, Chen L, Bhutta ZA, Cohen J, Crisp N, Evans T.....Zurayk H. Health professionals for a new century: transforming education to strengthen health systems in an interdependent world. The Lancet. 2010; 376: 1923-58.

Garner, B. (2019). Developing essential leadership skills through simulation. Organization Development Review. 2019; 51(2): 58-59.

Leape LL. Errors in medicine. Clinica Chimica Acta. 2009; 404(1): 2-5. doi: 10.1016/j.cca.2009.03.020.

Makary MA, Daniel M. Medical error - the third leading cause of death in the US. BMJ. 2016 353: doi: 10.1136/bmj.i2139.

Moore SM, Dolansky MA., Singh M, Palmieri P, Alemi F. The Systems 
Thinking Scale. Unpublished manuscript. 2010. Retrieved from: https://case.edu > nursing ¿ sites > case.edu.nursing , files , STS Manual

Plack MM, Goldman EF, Scott AR, et al. Systems thinking and systems-based practice across the health professions: An inquiry into definitions, teaching practices, and assessment. Teaching and Learning in Medicine. 2018; 30(3): 242-254. http://www.tandfonline.com/doi/abs/10.1080/10401334.2017.1398654. doi: 10.1080/10401334.2017.1398654.

Thorton-Bacon C, Trent P, McCoy T. Enhancing systems thinking for undergraduate nursing students using Friday Night at the ER. Journal of Nursing Education. 2018; 57(11): 987689.

Stalter A, Phillips J, Ruggiero J, Scardaville D, Merriam D, Dolansky M, ... Winegardner, S. (2017). A Concept Analysis of Systems Thinking. Nursing Forum. 2017; 52(4): 323-330.

Swanson R, Cattaneo A, Bradley E, Chunharas S, Atun R, Abbas, K, . . Best A. Rethinking health systems strengthening: Key systems thinking tools and strategies for transformational change. Health Policy and Planning. 2012;27(Supp14): Iv54-Iv61.

Vincent, C., \& Amalberti, R. Safer Healthcare Strategies for the Real World (1st ed. 2016. ed.). Cham: Springer International Publishing: Imprint: Springer; 2016

Waldman J, Schargel F. Twins in trouble (II): Systems thinking in healthcare and education. Total Quality Management \& Business Excellence. 2006; 17(1): 117-130.

Young J. Using a role-play simulation game to promote systems thinking. Journal of Continuing Education in Nursing. 2018; 49(1): 10-11. 
Table 1. Study Site Descriptions, and sample size

\begin{tabular}{ccc} 
Site Number & Description & $\sim \mathbf{N}^{*}$ \\
\hline 1 & $\begin{array}{c}\text { Private research university in } \\
\text { the southeastern U.S. }\end{array}$ & 596 \\
2 & $\begin{array}{c}\text { Public research university in the } \\
\text { midwestern U.S. }\end{array}$ & 247 \\
3 & $\begin{array}{c}\text { Public research university in the } \\
\text { mid -Atlantic U.S. }\end{array}$ & 56 \\
4 & $\begin{array}{c}\text { Private research university in } \\
\text { the midwestern U.S. } \\
5\end{array}$ & 20 \\
& $\begin{array}{c}\text { Private university in the } \\
\text { southeastern U.S. }\end{array}$
\end{tabular}

**N's reporting students participating in FNER sessions are approximations based on enrollment information provided from course instructors where FNER was included as part of the course.

Table 2. Participant demographics

\begin{tabular}{cc} 
Group & $\mathbf{N}$ \\
\hline \multirow{2}{*}{ Gender } & Male $=84$ \\
& Female $=315$ \\
& Med $=51$ \\
Discipline & Nurs $=318$ \\
Studied & PT $=20$ \\
& PH $=2$ \\
& Psy $=3$
\end{tabular}




\begin{tabular}{|c|c|}
\hline $\begin{array}{c}\text { Nursing Degree } \\
\text { Level }\end{array}$ & $\begin{array}{c}\mathrm{BSN}=218 \\
\mathrm{RN}-\mathrm{BSN}=47 \\
\text { Graduate }=1\end{array}$ \\
\hline $\begin{array}{l}\text { BSN Degree } \\
\text { Length }\end{array}$ & $\begin{array}{c}\mathrm{T}-\mathrm{BSN}=136 \\
\mathrm{AO}-\mathrm{BSN}=129\end{array}$ \\
\hline
\end{tabular}

Table 3. Between subjects interactions

\begin{tabular}{|c|c|c|c|c|c|}
\hline $\begin{array}{c}\text { Group } \\
\text { compared }\end{array}$ & Pre-Mean & Post -Mean & $\mathbf{F}$ & df & $\mathbf{p}$ \\
\hline Gender & $\begin{array}{c}\text { Male }=56.37 \\
\text { Female }=58.24\end{array}$ & $\begin{array}{c}\text { Male }=58.33 \\
\text { Female }=59.63\end{array}$ & .063 & 1 & .802 \\
\hline $\begin{array}{l}\text { Discipline } \\
\text { Studied }\end{array}$ & $\begin{array}{c}\text { Med }=56.12 \\
\text { Nurs }=58.52 \\
\text { PT }=55.20 \\
\text { PH }=53.50 \\
\text { Psy }=52.00\end{array}$ & $\begin{array}{c}\text { Med }=58.22 \\
\text { Nurs }=59.92 \\
\text { PT }=59.75 \\
\text { PH }=66.00 \\
\text { Psy }=54.33\end{array}$ & 1.91 & 5 & .092 \\
\hline $\begin{array}{l}\text { Nursing } \\
\text { Degree } \\
\text { Level }\end{array}$ & $\begin{aligned} \text { BSN } & =57.76 \\
\text { RN-BSN } & =56.17 \\
\text { Graduate } & =66.00\end{aligned}$ & $\begin{aligned} \mathrm{BSN} & =59.30 \\
\mathrm{RN}-\mathrm{BSN} & =57.17 \\
\text { Graduate } & =59.00\end{aligned}$ & .739 & 2 & .479 \\
\hline $\begin{array}{c}\text { BSN } \\
\text { Degree } \\
\text { Length }\end{array}$ & $\begin{array}{c}\mathrm{T}-\mathrm{BSN}=55.77 \\
\mathrm{AO}-\mathrm{BSN}=59.35\end{array}$ & $\begin{array}{c}\mathrm{T}-\mathrm{BSN}=57.48 \\
\mathrm{AO}-\mathrm{BSN}=60.46\end{array}$ & .432 & 1 & .512 \\
\hline
\end{tabular}

*Med. = medicine, Nurs. = nursing, PT $=$ Physical Therapy, PH = Public Health, Psy $=$ Psychology. T-BSN $=$ Traditional BSN, AO-BSN. **No matched pairs available for analysis for Pharmacy. 